\title{
Qualidade da Assistência em Planejamento Familiar na opinião de usuárias do Programa Saúde da Família*
}

\author{
Quality of Assisted Family Planning According to Opinion of Users of a Family Health Program.
}

Calidad de la asistencia en planificación familiar según la opinión de usuarias del Programa Salud de la Familia

\section{Escolástica Rejane Ferreira Moura1, Raimunda Magalhães da Silva ${ }^{2}$}

\begin{abstract}
RESUMO
Objetivo: avaliar a qualidade da assistência em planejamento familiar a partir de opiniões de usuárias do Programa Saúde da Família (PSF). Métodos: estudo avaliativo cujos dados foram coletados em oito municípios do Ceará, por meio de entrevista realizada com 50 usuárias e observação de campo. Os dados foram organizados pela técnica de análise categorial e analisados a luz da estrutura conceitual de Bruce. Resultados: a qualidade da assistência em planejamento familiar foi determinada por: orientação/informação aos clientes, envolvendo o casal; divulgação; oferta regular dos anticoncepcionais; fácil acesso; atendimento cordial; vínculo com a equipe do PSF; e cuidado diferenciado às mulheres com risco reprodutivo. Conclusão: a escuta ao cliente mostrou-se fundamental à avaliação da qualidade da assistência em planejamento familiar com enfoque nas necessidades dos usuários.

Descritores: Assistência; Qualidade; Avaliação; Planejamento familiar; Programa saúde da família
\end{abstract}

\begin{abstract}
Objective: to evaluate the quality of assisted family planning based on opinion of users of a Family Health Program. Methods: an exploratory design was used to conduct this study. Data were collected in eight Ceara State cities through face-to-face interviews and field observations with 50 females. Data analysis consisted of categorical analysis technique in the light of Bruce's conceptual structure. Results: quality of Assisted family planning was determined by orientation/instruction to users, couple involvement, divulgation, regular offering of contraceptive practices, easy access to care, friendly customer service, access to the Family Health Program team; and special care to women with reproductive risk. Conclusion: user comments suggested that it is fundamental to evaluate the quality of assisted family planning based on the users' needs.
\end{abstract}

Keywords: Assistance; Quality; Evaluation; Family planning; Family health program

\section{RESUMEN}

Objetivo: evaluar la calidad de la asistencia en planificación familiar a partir de la opinión de usuarias del Programa Salud de la Familia. Métodos: estudio evaluativo cuyos datos fueron recolectados en ocho municipios de Ceará, por medio de una entrevista realizada a 50 usuarias y observación de campo. Los resultados fueron organizados por la técnica de análisis de categorías y analizados a la luz de la estructura conceptual de Bruce. Resultados: la calidad de la asistencia en planificación familiar fue determinada por: orientación/información a los clientes, incluyendo a la pareja; divulgación; oferta regular de los anticonceptivos; fácil acceso; atención cordial; vínculo del equipo del PSF; y cuidado diferenciado a las mujeres con riesgo reproductivo. Conclusion: el escuchar al cliente se mostró fundamental para la evaluación de la calidad de la asistencia en planificación familiar con enfoque en las necesidades de los usuarios.

Descriptores: Asistencia; Calidad; Evaluación; Planificación familiar; Programa salud de la familia

\footnotetext{
*Trabalho baseado em tese de doutorado apresentada à Universidade Federal do Ceará- UFC - Fortaleza (CE), Brasil, em 2003. Apoiado por meio de bolsa de demanda social da Fundação Cearense de Apoio ao Desenvolvimento Cientifico e Tecnológico (FUNCAP).

${ }^{1}$ Doutora em Enfermagem. Universidade Federal do Ceará - UFC - Fortaleza (CE), Brasil.

${ }^{2}$ Doutora em Enfermagem. Coordenadora do Mestrado em Educação - Universidade de Fortaleza -UNIFOR - Fortaleza (CE), Brasil.
} 


\section{INTRODUÇÃO}

A assistência relacionada ao planejamento familiar (PF), no Brasil, está regulamentada pela Lei n. ${ }^{\circ}$ 9.263/96 que determina ações pautadas nos direitos reprodutivos, de forma a garantir às mulheres e aos homens cuidados preventivos e educativos, meios, métodos e técnicas disponíveis para a regulação da fecundidade, seja com a finalidade de limitar ou aumentar a prole ${ }^{(1)}$. É importante lembrar que o PF foi preconizado pelo Ministério da Saúde (MS), em 1984, como uma das áreas prioritárias do Programa de Assistência Integral à Saúde da Mulher, devendo garantir o acesso aos meios de contracepção e concepção ou o acompanhamento clínico-ginecológico e ações educativas, para que as escolhas dos usuários sejam conscientes $^{(2)}$.

Atualmente, o PF é uma das sete áreas estabelecidas pela Norma Operacional da Assistência (NOAS-2001) a ser oferecida por todos os municípios brasileiros como responsabilidade da atenção primária à saúde, levada às populações por meio das equipes do Programa Saúde da Família (PSF) ${ }^{(3)}$.

Em face ao exposto, ressalta-se que uma das diretrizes básicas do PSF é a participação comunitária, ou seja, que as equipes desenvolvam suas atividades em planejamento conjunto com as famílias adstritas, e que o usuário tenha voz nas decisões sobre os serviços de saúde, manifestando suas opiniões e seus pontos de vista. Aliás, a escuta ao usuário tem se constituído em uma atividade relevante na atualidade, uma vez que o exercício da cidadania é uma das atribuições dos profissionais que atuam no PSF, a incluir a convocação para o exercício do controle sobre os serviços de saúde. Neste sentido, uma indagação foi suscitada: o que seria um serviço de planejamento familiar de qualidade para os usuários do PSF?

A respeito de qualidade em PF, uma estrutura conceitual subsidia sua avaliação, estabelecendo o cliente como enfoque principal. A referida estrutura determina que os principais elementos que constituem a qualidade dos serviços de PF são: oferta/escolha dos métodos anticoncepcionais (MACs), informação aos usuários, competência técnica profissional, relações interpessoais profissional-cliente, mecanismos de acompanhamento dos usuários e rede apropriada dos serviços. Estes elementos refletem seis aspectos dos serviços que os clientes experimentam como críticos, representando um ponto de partida requisitado para desenvolver uma descrição dos serviços oferecidos e para avaliar sua qualidade ${ }^{(4)}$. Assim, tomando por base o respectivo referencial, decidiu-se pela realização deste estudo que traz como objetivo avaliar a qualidade da assistência em planejamento familiar a partir de opiniões de usuárias do Programa Saúde da Família (PSF).

\section{MÉTODOS}

Trata-se de estudo do tipo pesquisa de avaliação, classificação proposta por García-Nuñes ${ }^{(5)}$ ao tratar especificamente sobre avaliação em planejamento familiar. Para este autor, uma avaliação mostra o que funciona e o que não funciona, o que devemos manter ou mudar, constituindo-se em um instrumento para a tomada de decisão, sendo utilizada, ainda, para responder a perguntas específicas sobre as necessidades, os processos, os resultados, a eficiência e o impacto de uma ação ou programa. A pesquisa de avaliação tem o propósito de averiguar quão bem está se desenvolvendo uma atividade com vistas a encontrar respostas para questões práticas ${ }^{(\sigma)}$. Portanto, é fundamental a avaliação de serviços de planejamento familiar, para reconhecer o que está bem e o que precisa ser modificado, garantindo subsídios à melhoria do atendimento das expectativas e necessidades dos usuários.

O universo do estudo compreendeu uma regional de saúde do Ceará composta por oito municípios (Aratuba, Mulungu, Guaramiranga, Pacoti, Baturité, Itapíuna, Capistrano e Aracoiaba), nos quais atuavam 32 equipes de PSF, o correspondente a 30.116 famílias cadastradas e $87,8 \%$ de cobertura ${ }^{(7)}$.

Os dados foram coletados por meio de entrevistas realizadas com 50 mulheres que aguardavam consultas em planejamento familiar em 16 unidades de saúde da família (USFs) da região (50\%), no período de julho a setembro de 2003. Foram incluídas oito unidades das sedes dos municípios e pelo menos uma unidade de área rural de cada município. Paralelamente, realizou-se a observação com utilização de um diário de campo, registrando-se dados relevantes à discussão dos resultados.

O número de usuárias foi delimitado pela saturação das falas, ou seja, a coleta de opiniões foi iniciada sem predeterminação do número de participantes e a amostra foi considerada satisfatória a partir da repetição das informações, de maneira que a pesquisadora não mais obtivesse dados novos ${ }^{(8)}$.

As usuárias foram convidadas a participar do estudo no ambiente da sala de espera e, naturalmente, conforme a disponibilidade de tempo, a ordem da chamada para o atendimento, e até mesmo o interesse e a curiosidade em participar, estas foram aderindo ao estudo. Participaram entre três e quatro mulheres por unidade, quantidade que permitiu uma interação tranqüila e suficiente da pesquisadora com os sujeitos do estudo durante as entrevistas, que seguiram uma única questão norteadora: "o que é um serviço de planejamento familiar de qualidade para a senhora?”. As falas foram redigidas concomitantemente pela pesquisadora.

Estas foram organizadas para a análise pelo Método de Análise de Conteúdo, seguindo a técnica de análise 
categorial proposta por Bardin, fases de pré-análise, exploração do material e interpretação ${ }^{(9)}$. Na pré-análise, os dados foram agrupados pelo uso da lógica, da intuição e experiências e conhecimentos acumulados da pesquisadora sobre a temática, fazendo-se repetidas leituras dos conteúdos, identificando pontos de semelhanças. $\mathrm{Na}$ fase da exploração do material, a fala de cada sujeito foi codificada pela letra "U" de usuário e numerada de 1 a 50 para facilitar a contagem dos eventos. Realizou-se uma leitura de todo o material, com a intenção de dividí-lo em unidades de significados convergentes e divergentes, tendo sempre em vista o contexto maior do estudo, ou seja, os seis elementos da qualidade da assistência ao PF proposto por Bruce ${ }^{(4)}$. Na interpretação, os resultados brutos ganharam significado para responder ao objetivo proposto.

O projeto de pesquisa foi aprovado pelo Comitê de Ética em Pesquisa (Comepe) do Complexo Hospitalar da Universidade Federal do Ceará, em conformidade com as diretrizes e normas regulamentadoras de pesquisas envolvendo seres humanos, do Conselho Nacional de Saúde - Ministério da Saúde, segundo Resolução n. ${ }^{\circ}$ 196/ $96^{(10)}$. O acesso aos municípios e respectivas USFs foi efetuado com a autorização dos secretários municipais de saúde, mediante contato pessoal prévio e apresentação formal através de carta de apresentação. Às participantes da pesquisa foram garantidas a confidencialidade e a privacidade, a proteção da imagem, a não-estigmatização e a não-utilização das informações em prejuízo das pessoas e/ou das comunidades. A estas foi apresentado o Termo de Consentimento Livre e Esclarecido, contendo informações sobre justificativa, objetivos e procedimentos que foram utilizados na pesquisa, através de linguagem acessível aos respondentes. Cada participante assinou ou identificou por impressão dactiloscópica o referido termo, em duas vias, ficando uma via retida pelo sujeito da pesquisa e uma segunda arquivada pelas pesquisadoras.

\section{RESULTADOS}

Um serviço de planejamento familiar de qualidade ficou caracterizado, na visão das usuárias, como aquele que presta orientação/informação (15), envolvendo o casal (4) e que divulga para que as pessoas tomem conhecimento para procurá-lo (3); que não deixa os métodos faltarem (9) e oferece os métodos anticoncepcionais (MACs) que as mulheres desejam (9); que leva o serviço para mais próximo de onde as pessoas vivem (7); que facilita a entrega (5); que trata bem a clientela (2); que a equipe de saúde é duradoura (1); e que se preocupa com as mulheres de risco (1). Sete (14\%) mulheres não expressaram suas opiniões quanto à qualidade do serviço de planejamento familiar, porém sem definir critérios, apontaram o serviço recebido como: "ta bom assim mesmo", "ta muito bem"; e uma outra falou: "não sei dizer nada não".

$\mathrm{Na}$ dimensão da orientação / informação, as usuárias ressaltaram o aspecto de oferecer orientação aos clientes já inseridos nos serviços de planejamento familiar, a incluir informações sobre os métodos anticoncepcionais, modo de uso, funcionamento e outros; e a divulgação ou a "propaganda" do serviço para a captação daqueles usuários que ainda estão sem assistência.

Quanto ao primeiro aspecto, o de informar os usuários internos quanto aos MACs, as mulheres expressaram a importância da conversa, da orientação e da escuta de suas necessidades. Enfocaram que, em geral, as mulheres são desinformadas sobre o planejamento familiar, marcadamente as adolescentes, o que está relacionado a "vergonha de falar nessas coisas". As falas que se seguem ilustram bem essa realidade:

Que conversassem mais com a gente, pra gente ser mais orientada. Explicassem direitinho pra gente conbecer todos os métodos (U2, U39).

Que dê mais orientação, tá pouquíssima (U5).

Era ter uma pessoa que escutasse e explicasse direito. Tem muita gente por aí que não tem informação nenbuma. O povo daqui tem vergonba de falar nessas coisas [referindo-se aos métodos anticoncepcionais] (U16).

Que tivesse as palestras, os grupos. O que tem de mulher aqui engravidando por falta de orientação! Elas têm vergonha de perguntar (U37).

Sempre haver palestras. Aqui existem muitas mulheres analfabetas. As mulheres, as mocinhas não sabem usar a camisinha... (U40).

Era pra ter mais reuniōes... as adolescentes, principalmente, não conhecem essas coisas [referindo-se aos métodos] (U43).

Uma especificidade destacada por algumas das mulheres como critério de qualidade de um serviço de planejamento familiar foi o envolvimento dos homens nas atividades informativas, ao argumentarem:

Era um serviço que tivesse alguma palestra para os homens, porque a gente escuta tudo aqui, sai acreditando, ai quando chega em casa eles [referindo-se aos maridos] botam tudo abaixo (U3), não acreditam de jeito nenhum na gente (U29).

Que elas [as enfermeiras] dessem mais palestras para os casais (U21).

A maioria dos maridos é da agricultura, não conhece essas coisas. Poderiam ser feitas palestras com os homens à noite (U50).

Ainda com relação a dar orientação / informação em PF uma mulher sugeriu que "os encontros deveriam incentivar mais, não ser aquela coisa pacata de reunião, pois todo mundo tem medo de reunião; que fosse mais convidativo que chamasse mais atenção, divertido" (U20).

Sobre o segundo aspecto, o da divulgação do serviço, as usuárias relacionaram-no, com a importância de trazer 
para o atendimento pessoas que sequer sabem da existência dos MACs, como as mulheres que moram em áreas rurais, nos sítios, distantes das sedes dos municípios:

Era um serviço que convocasse as pessoas a virem. Há muitas campanhas, mas sobre o planejamento familiar é muito sem propaganda (U1).

Era o posto divulgar mais... tem muita mulher que não usa nada (U34).

Era pra eles [a Equipe de Saúde da Família] procurar a gente nos sitios. Nós não sabemos dessas coisas [sobre os MACs]... como eu, são muitas (U23).

Nas falas seguintes, as mulheres enfatizaram a entrega regular dos MACs como parte da qualidade, no sentido de que os métodos não faltem no serviço e que tenha continuidade na oferta:

Que não faltasse a camisinha (U5, U27), a pilula (U11 e U19) e a injeção (U13).

Que não faltem os anticoncepcionais, que tenha continuidade (U8).

Ser fiel ao que eles já fornecem, sem deixar faltar (U12, U15, U17).

Quanto à oferta/variedade foi ressaltado que um serviço que tem qualidade deve disponibilizar os métodos que as mulheres precisam e desejam:

Que oferecessem todos os métodos que a gente precisasse (U4): que tivesse a injeção (U2, U42);

Que o serviço se preocupasse com as mulheres que não se dão com o comprimido, dando outros meios de evitar filhos (U14).

O melhor serviço de planejamento familiar é aquele que entrega tudo [referindo-se aos MACs] (U50).

Um aspecto também destacado neste contexto da oferta foi o da garantia da livre escolha e da facilidade de acesso aos métodos, cujas mulheres destacaram a dificuldade de acesso aos métodos cirúrgicos, inclusive um direito assegurado na Lei n. ${ }^{\circ}$ 9.263/96 "a homens ou mulheres com capacidade civil plena e maiores de 25 anos de idade ou, pelo menos, com dois filhos vivos" (1):

Era atender do nosso jeito. Meu marido diz que tem coragem de fazer a vasectomia, mas conseguir aonde? [Faz um gesto de negação]... aqui até a ligação que já é mais conhecida, eles [referindo-se a unidade de saúde da região que realiza a cirurgia] botam a maior dificuldade (U16, U22, U29).

Eles deviam ligar aquelas pessoas que já tiveram familia demais, não tem outro jeito (U46).

Ainda com relação à oferta, uma usuária chamou a atenção para mais uma particularidade da qualidade do serviço: dar atenção prioritária às mulheres com risco reprodutivo: "o agente de saúde deveria se responsabilizar mais pelas pessoas que não toma muito cuidado. Tenho uma vizinha que teve gêmeos há menos de dois anos e já está grávida de novo" (U32).

A descentralização dos serviços para as localidades foi um aspecto da qualidade defendido pelas mulheres que ainda sofrem a falta de transporte, a falta de recursos financeiros para pagar uma passagem, problemas de acesso geográfico, enfim, a negação do princípio de acessibilidade que norteia o SUS:

Pra gente ir pra cidade é longe, é melhor ser atendida aqui (U8, U38).

Que viesse o DIU pra gente botar aqui mesmo [referindo-se a sede do município] (U35), pois não temos a passagem para nos deslocar (U44).

Até onde a doutora vai de $15 \mathrm{em} 15$ dias ainda é longe pra gente. Da última vez en fui, ela falton e tudo isso deixa a gente de fora (U45).

A facilidade no recebimento dos MACs foi salientada pelas mulheres, que defenderam a entrega descentralizada (pelo agente de saúde), em quantidade suficiente para uso em período mais longo (pelo menos três meses) e com rapidez, sem grandes esperas:

Que a gente recebesse os métodos pelo menos pra três meses. A gente é ocupada, tem muita luta em casa... se eu tivesse posse pra comprar eu num vinha não (U6, U24); e que fosse rápido (U28).

No meu pensar se ela [a enfermeira] despachasse duas ou três caixas era melhor. A gente é muito ocupada, todo mês tem que tirar aquele tempo de vir na unidade. Isso é ruim, né! (U10, U43).

Eu tenho vontade de botar o DIU só pra não ta todo mês nesse Posto atrás de comprimido (U22).

Poderia as agentes de saúde levar as camisinhas para as localidades pra ser mais fácil. Nem todo mês a gente pode sair (U43). Minha amiga tem cinco meninos, ela não pode ta saindo (U47).

O relacionamento interpessoal foi ressaltado como padrão de qualidade na medida em que garantisse um tratamento igual e que a equipe de saúde fosse simpática.

Que ela [referindo-se a profissional] continue tratando todo mundo bem. Pra ela não tem diferença (U13).

Todas são simpáticas com a gente. Não tenho o que falar (U26)

Uma usuária enfatizou a importância de garantir a permanência da equipe de PSF na área, de maneira a favorecer o vínculo com as pessoas e com as famílias:

Era ele [referindo-se às equipes de PSF] durarem mais, pois não dá nem tempo a gente se acostumar com eles já vem outros (U19).

\section{DISCUSSÃO}

Conforme a estrutura conceitual da qualidade em planejamento familiar, dar orientação/informação em 
planejamento familiar envolve três componentes principais: proporcionar aos clientes a apreciação dos métodos anticoncepcionais e de suas principais características; seu emprego eficaz, de modo a reconhecer que o método pode provocar alterações físicas saudáveis ou não saudáveis e interferir em atividades cotidianas, inclusive na sexualidade do casal; e desenvolver no cliente uma expectativa apropriada a respeito do que o serviço de saúde oferece e garante ${ }^{(4)}$. O MS reafirma o pensamento da autora, ao determinar que os conhecimentos necessários para a escolha e posterior utilização do método anticoncepcional devem ser trabalhados com a clientela do planejamento familiar, inclusive proporcionando o questionamento e a reflexão sobre a sexualidade ${ }^{(1)}$. Ressalta-se, neste contexto, que os profissionais de saúde raramente lembram de que pode haver uma diferença entre o que eles acreditam ser necessidade dos clientes e o que estes realmente desejam como perspectivas pessoais ${ }^{(1)}$. Essa percepção profissional vem atrelada à conduta passiva da maioria dos clientes, que aceita as decisões profissionais, pois também partem do princípio de que o saber profissional é soberano, não tendo, o cliente, condições de avaliar o que poderia ser melhor para si mesmo. Dias ${ }^{(12)}$ declara que as mulheres das classes populares são criadoras e repassadoras de um saber em saúde, em razão da experiência de vida como mães e donas de casa. O saber popular das mulheres, em decorrência das estratégias utilizadas para superar a escassez de recursos ao longo de suas vidas, tem seu valor e é eficiente na manutenção das condições mínimas de saúde. Neste sentido, a autora percebe duas origens no saber popular: uma mais externa, mais influenciada pela classe dominante, instituições como escolas e meios de comunicação de massa; e outra origem que se constrói mais internamente e é própria às suas condições de classe dominada. Estas duas origens convivem no interior de todo saber popular que precisa ser valorizado pelos profissionais de saúde para obtenção de resultados mais efetivos na interação com os clientes.

Essa abordagem vem ao encontro do que as mulheres expressaram, ao identificarem a orientação/informação como uma condição de qualidade dos serviços de PF. Suas falas revelaram conviver com a desinformação a respeito dos MACs, o uso correto dos mesmos, bem como a "vergonha" que representa uma barreira para que mulheres e adolescentes procurem se inteirar do assunto.

Foi dado o indicativo para que as informações fossem oferecidas em grupo e de maneira mais atrativa, sobre o que destacaram como sendo uma oportunidade de proporcionar às pessoas condições para o desenvolvimento de sua própria mudança. No grupo a interação é particularmente realizada entre os participantes, que pouco a pouco passam a assumir papel ativo no decorrer do processo, decidindo, inclusive, sobre a prioridade dos assuntos que querem discutir ${ }^{(13)}$. Neste contexto, a força para a mudança provém dos participantes do grupo. Um indivíduo motivado fortalece a disposição do outro para engajar-se de forma mais efetiva na busca da transformação, ajudando a vencer a "vergonha" presente neste universo.

Sobre o envolvimento dos maridos nas atividades informativas, que é por demais importante, as mulheres foram induzidas pelo poder masculino ao afirmarem "botam tudo abaixo" ou "não acreditam de jeito nenhum na gente", aspecto que deve ser trabalhado durante as atividades de orientação / informação na perspectiva de minimizar desigualdades nas relações entre os gêneros.

A sugestão para o desenvolvimento de atividades noturnas é possível de ser posta em prática, uma vez que 89,7\% dos enfermeiros já residem no município e/ou na localidade de sua atuação. Esta condição também foi pauta de discussão em uma pré-conferência e duas conferências municipais de saúde, no universo do estudo. Os usuários discutiram a possibilidade de atendimento das 18 às 20 horas alguns dias na semana, de forma que o profissional compensasse seu horário e ao mesmo tempo pudesse envolver o usuário e trabalhador nas atividades do setor, como é essa do planejamento familiar (diário de campo).

É importante destacar o que as mulheres acrescentaram sobre a etapa de divulgação e captação daqueles usuários que estão fora do sistema, o que recai sobre o pensamento de Bruce $^{(4)}$ ao afirmar que o serviço deve ser suficiente para uma base populacional. Este aspecto corresponde ao princípio de organização do PSF, ou seja, atender um número de famílias delimitado, de um território também delimitado, favorecendo o cadastramento e a busca da população-alvo para cada tipo de cuidado.

A oferta dos MACs deve estar embasada em uma variedade que permita atender o interesse e a necessidade de subgrupos diferentes, envolvendo adolescentes, mulheres na perimenopausa, em pós-parto ou pós-aborto e nutrizes. Deve-se observar, ainda, as características individuais de intolerância aos hormonais, da nãoadaptação ao uso do preservativo, da necessidade de uso de método muito seguro em virtude da existência de fatores de risco para uma futura gestação, e/ou da opção pelo método natural ou pelos métodos comportamentais, dentre outras ${ }^{(4)}$. Outro aspecto para o qual Bruce ${ }^{(4)}$ chama a atenção, diz respeito à garantia regular dos anticoncepcionais e que estes sejam suficientes para uma base populacional ou geográfica estabelecida, de forma que as pessoas tenham acesso igual. Essa contextualização foi contemplada pelas usuárias ao defenderem a disponibilidade dos métodos desejados, que elas precisassem e que não faltassem, que o serviço fosse "fiel" naquilo que oferecesse. 
Para Bruce ${ }^{(4)}$, os serviços de planejamento familiar estão mais voltados para o recrutamento dos clientes do que para o acompanhamento, determinando elevada descontinuidade no uso dos anticoncepcionais. A mesma autora acrescenta que, para garantir o retorno e acompanhamento do cliente, é fundamental melhorar o acesso e reduzir o tempo de espera para o atendimento. Neste sentido, as mulheres verbalizaram suas realidades com veemência, demonstrando a necessidade de maior descentralização dos serviços, de maneira a chegar cada vez mais perto de onde moram, bem como a participação do agente comunitário de saúde na entrega subseqüente e a entrega em maior quantidade, de maneira a não estar vinculada a uma visita mensal ã unidade de saúde. O comentário de um médico do PSF corrobora essa realidade, ao afirmar que as condições de transporte e de estradas na sua área eram precárias e que estando há um ano na equipe, ainda desconhecia duas das localidades de seu território de abrangência por dificuldade geográfica de acesso (diário de campo), fazendo perceber que nas áreas rurais os serviços são mais escassos. Portanto, apesar da cobertura de $87,8 \%$ da população do universo do estudo por equipes de PSF, a acessibilidade ao serviço de planejamento familiar ainda permanece como uma barreira a ser minimizada, principalmente para as famílias que residem em áreas rurais.

Observou-se que a entrega dos MACs, tanto de primeira vez quanto de seguimento, independente do método, está associada a uma consulta, iniciativa desnecessária e que contribui para a morosidade no atendimento e na formação de filas nos serviços, bem como para a sobrecarga profissional e insatisfação das usuárias (diário de campo). Sobre este assunto, autores ressaltam que uma variedade de profissionais pode oferecer métodos de planejamento familiar. Em diversos países, além do médico, enfermeiros, auxiliares e técnicos de enfermagem, agentes de saúde, parteiras tradicionais, educadores, membros da comunidade e usuários experientes de métodos anticoncepcionais, habitualmente oferecem serviços de planejamento familiar. Para tanto, é oferecida capacitação adequada, sendo ditadas determinadas regras sobre quem pode oferecer tais métodos ${ }^{(14)}$. Na visão dos mesmos autores, a pílula combinada e a pílula somente de progestágeno, o preservativo masculino, os espermaticidas, os métodos comportamentais e a lactação com amenorréia (LAM) podem ser oferecidos por todos os que foram citados; os injetáveis, por qualquer pessoa treinada na aplicação; o diafragma, por qualquer provedor treinado para realizar exames pélvicos e medir seu tamanho; o DIU pode ser inserido por médicos, enfermeiros e obstetrizes treinadas. Apesar de os autores não terem tratado sobre o preservativo feminino, defendemos a idéia de que este método possa ser oferecido por qualquer uma das pessoas citadas e, principalmente, por usuárias experientes $^{(14)}$.

Apesar de a inserção do DIU ser um procedimento plenamente praticável no nível primário da atenção, na região estudada não se praticava desta forma. Quatro municípios contavam com profissionais habilitados para realizar a inserção. Os demais tinham o Centro de Saúde de Baturité como referência, porém o ginecologista só atendia uma vez por semana, o que tornava o acesso das mulheres bastante limitado (diário de campo). Essa situação crítica poderia ser amenizada por meio de uma supervisão regional, envolvendo dois aspectos: primeiro, remanejando o DIU para os municípios que dispõem de profissional habilitado para inserção; segundo, promovendo a capacitação de médicos e enfermeiros para realizarem a inserção nos demais municípios. Este treinamento poderia ser realizado pelos próprios médicos da região, já treinados, atendendo inclusive a necessidade daquelas mulheres que aguardam por uma inserção. Destaca-se, neste ponto, que a regional de saúde é um espaço geográfico populacional composto por um conjunto de municípios agrupados por afinidades de prestação de serviços, cuja articulação visa encontrar soluções para problemas comuns na área da saúde e garantir uma assistência integral em uma rede apropriada de serviços, por meio de pactuação e negociação ${ }^{(15)}$.

A relação interpessoal profissional-cliente deve ser estabelecida com simpatia, confiança e garantia de disponibilidade por parte do profissional mediante qualquer dúvida ou intercorrência por parte dos clientes. Por outro lado, os profissionais precisam conhecer a realidade socioeconômica e cultural das pessoas, para ter uma dimensão do que ensinar e como ensinar, por meio de uma relação horizontal de troca, que valorize o saber existente sobre o planejamento familiar. Neste contexto, o relacionamento interpessoal positivo influencia a confiança dos clientes em suas próprias escolhas, gerando satisfação nos usuários e maiores chances de retorno e adesão aos serviços. Para muitos clientes, "ser mal tratado" é pior do que não receber qualquer tipo de cuidado $^{(4)}$.

As usuárias enfocaram a simpatia, tratar bem, com igualdade, atitudes esperadas em um serviço de qualidade, bem como a permanência das equipes de PSF por maior tempo nas comunidades, de maneira a favorecer o vínculo e a integração.

\section{CONCLUSÃO}

A voz dessas mulheres permitiu reconhecer a importância de valorizar a escuta aos usuários e recomendar às equipes de PSF, em geral, que criem condições para esta iniciativa, no sentido de obter opiniões e sugestões dos caminhos mais adequados à 
melhoria da qualidade da assistência em planejamento familiar, com a certeza de se aproximar ao máximo das necessidades e expectativas da população alvo.

As participantes apontaram os seguintes elementos como determinantes da qualidade de serviços de planejamento familiar: orientação/informação aos clientes, envolvendo o casal; divulgação do serviço e captação das pessoas; continuidade e oferta dos métodos anticoncepcionais que as mulheres desejam; serviço próximo de onde as pessoas vivem; facilidade no recebimento do método; bom tratamento a clientela; equipe de PSF permanente; e cuidado diferenciado às mulheres de risco ${ }^{(16)}$. Portanto, os pontos de vista das usuárias foram convergentes aos elementos da qualidade descritos por Bruce ${ }^{(4)}$, ampliando, todavia, a visão para o campo da participação masculina, o enfoque de risco, a vinculação com a equipe de PSF e a facilidade de acesso ao serviço.

\section{REFERÊNCIAS}

1. Brasil. Ministério da Saúde. Planejamento familiar: manual para o gestor. Brasília: Ministério da Saúde; 2002. (Série A. Normas e Manuais Técnicos).

2. Brasil, Minstério da Saúde. Secretaria de Políticas de Saúde. Área Técnica de Saúde da Mulher. Assistência em planejamento familiar: manual técnico. 4a ed. Brasília: Ministério da Saúde; 2002. (Série A. Normas e Manuais Técnicos, n. 40).

3. Brasil. Ministério da Saúde. Norma Operacional da Assistência à Saúde - NOAS-SUS 01/2001. Brasília; 2001.

4. Bruce J. Fundamental elements of the quality of care: a simple framework. Stud Fam Plann. 1990; 21(2):61-91.
5. García-Nunez J. Avaliação em planejamento familiar: um guia para administradores e avaliadores. Salvador: Pathfinder Internacional; 1993.

6. Polit DF, Beck CT, Hungler BP. Compreensão do delineamento da pesquisa quantitativa. In: Polit DF, Beck CT, Hungler BP. Fundamentos de pesquisa em enfermagem: métodos, avaliação e utilização. 5a. ed. Porto Alegre: Artmed; 2004. cap. 8, p. 162-198.

7. Ceará. Secretaria da Saúde. Sistema de informação da atenção básica (SIAB). Fortaleza: Núcleo de Informação em Saúde; 2003.

8. Trentini M, Paim L. Pesquisa em enfermagem: uma modalidade convergente-assistencial. Florianópolis: UFSC; 1999.

9. Bardin L. Análise de conteúdo. Lisboa: Edições 70; 1979.

10. Brasil. Ministério da Saúde. Conselho Nacional de Saúde. Comissão Nacional de Ética em Pesquisa (CONEP). Resolução $\mathrm{n}^{\circ}$ 196/96 sobre pesquisa envolvendo seres humanos. Brasília; 24 p.

11. Faúndes A, Hardy E. Ética médica e planejamento familiar no Brasil. Bioética. 1996; 4(2): 221-6.

12. Dias NMO. Mulheres, "sanitaristas de pés descalços". São Paulo: HUCITEC; c1991. (Série Saúde em debate, 44).

13. Bechelli LPC, Santos MA. Psicoterapia de grupo e considerações sobre o paciente como agente da própria mudança. Rev Latinoam Enfermagem. 2002;10(3): 383-91.

14. Hatcher RA, Rinehart W, Blackburn R, Geller JS, Shelton JD. Pontos essenciais da tecnologia de anticoncepção. Baltimore: Universidade Johns Hopkins. Escola de Higiene e Saúde Pública. Centro de Programas de Comunicação; 2001. cap. 2, p. 2-1-2-2.

15. Fonseca Neto MD, Vilar MCPM. Sistemas microrregionais de serviços de saúde: uma estratégia de reorganização do SUS - Ceará. Fortaleza: SESA; 2002. 